\title{
Process of Developing Characters in an Eastern Story
}

\author{
Hsiang-Lien Lee1, Chun-Hung Liu² \\ ${ }^{1}$ Department of Visual Art and Design, National Tainan University, Taiwan \\ ${ }^{2}$ Department of Education Industry and Digital Media, National Taitung University, Taiwan \\ Email: elen@mail.nutn.edu.tw, chliu@nttu.edu.tw
}

How to cite this paper: Lee, H.-L., \& Liu, C.-H. (2022). Process of Developing Characters in an Eastern Story. Art and Design Review, 10, 56-71.

https://doi.org/10.4236/adr.2022.101006

Received: September 6, 2021

Accepted: January 24, 2022

Published: January 27, 2022

Copyright (c) 2022 by author(s) and Scientific Research Publishing Inc. This work is licensed under the Creative Commons Attribution International License (CC BY 4.0).

http://creativecommons.org/licenses/by/4.0/

\begin{abstract}
The Chinese classic novel Romance of the Three Kingdoms has been reinterpreted by various authors and adapted into different media. In the novel, character images were shaped and the peculiarity of the characters' characteristics was depicted by describing their behavior. This study uses Eastern and Western narrative theories to classify the character development (characterization) methods that various creators employed on this Chinese story in three distinct media (i.e., novel, antique book with illustrations, and temple painting). Thus, this study aims to identify the creation processes involved in characterization when adapting a literary work with substantial textual content. By integrating the results on Eastern and Western narratology approaches, a characterization method for the preproduction stage of animation was proposed. This explanation may serve as a reference for animation education and for creativity practices.
\end{abstract}

\section{Keywords}

Characterization, Pictorial Narrative, Intermediality

\section{Introduction and Motivation}

Images convey messages. Stanczak (2007) proposed several questions regarding the purpose of images: How do images convey messages? What messages are conveyed? To whom are they conveyed? Pictorial narrative relies on various media, including pictures, video images, paintings, and text, to disseminate messages (Ryan, 2004). Text and images are different forms of narrative media; they convey distinct messages. They can be used to develop two distinct linear processes of creation, but can also be regarded as a single linear sequence of messages; for instance, a novel may be adapted into films, illustrations, and animations. The 
Secret World of Arrietty, a Japanese animated film produced by Studio Ghibli, is an adaptation of The Borrowers by Mary Norton, a British fantasy novel. Overall, the animation is slightly different from the original novel but they share similar plots and concepts. The film was produced in the aesthetic style that Studio Ghibli has been consistently known for, namely a style that incorporates Japanese and Western elements. Russian animator and animation director Aleksandr Petrov is known for his ability to transform literature using oil painting techniques that create a romantic and sentimental atmosphere in animation, one example being his animated adaptation of The Old Man and the Sea, a novel by Ernest Hemingway. As creators, screenplay adapters face the challenge of brainstorming which elements from the original novel to retain and disregard in the adapted animation screenplay. To complete an animated work, visual designers must undertake a series of procedures (e.g., conceptual design, character design, setting design, and storyboarding) that require teamwork and the division of labor according to professional expertise. Independent animators, including student animators studying in departments of animation design, outnumber commercial animators. Starting from a novel full of textual passages, how does a creator select a subset of textual passages to create images? Do the images created faithfully convey the essence of the story? This adaptation process challenges the creator's ability to use images to interpret the original work, a process of transposition. Depending on lifestyle, religion, and cultural background, one viewer perceives an image differently than another viewer does. For instance, Persepolis is a feature-length French animated film based on Marjane Satrapi's graphic novel of the same name; a story of Islam and women set in Iran.

Narrative theories have long been proposed in Eastern and Western academia. Western narratology emphasizes objective discussion and systematic and logical classification systems; Chinese narratology focuses on the following dimensions: themes, plot structures, character types, narrative perspectives, narrative time and space (Ryu, 2011). By incorporating Western and Eastern narrative theories, literary scholars in Eastern countries have applied the combined results to researching Chinese mythology and various novels. Western and Eastern narrative theories classify characters into distinct types with different logics. A text depicts a character's explicit and implicit characteristics; the transformation of those characteristics into visual images is a process that can challenge the sensory perception capacities of both the image creator (sender) and viewer (receiver). How do the creator and viewer utilize the visual elements of the original text and the images adapted from the text to construct the narrative structure? The intermediality of both media is a topic worthy of exploration. This study examined the process of "character development" (characterization) in text-to-image translation by using the story of the Chinese novel, Romance of the Three Kingdoms. The objectives of this study are: 1) to compare the definitions of "characterization" between Eastern and Western narrative theories, and 2) to derive a method of characterization by applying the characterization methods employed in the 
text of a Chinese classic novel to the narratology of static and dynamic images. The results of this study can serve as a reference for characterization across two media, specifically, from text to image.

\section{Theoretical Framework}

\subsection{Eastern and Western Narrative Theries}

The concept of narratology originated from Russian formalism. Propp (1975) analyzed the narrative structures of folktales with various motifs and identified 31 functions and 7 types of characters. Later, Rimmon-Kenan (1983) divided narratives into the dimensions of story and text and provided her definitions of characters and characterization. A story is made of events and existents. Events can be classified into actions and happenings; existents can be categorized into characters and settings (Chatman, 2000). In today's Western narrative theory, scholars have expanded the possibilities beyond those of early narrative theories; for instance, a work can be adapted into various forms of media but contain the same events and existents, which can be perceived by the audience. The animated films mentioned in the preceding section are apt examples of adaptations across the media of novels, graphic novels, and animations. The story of Notre-Dame de Paris (The Hunchback of Notre-Dame) by Victor Hugo has enjoyed widespread and rapid international dissemination in the form of animations and musicals. This suggests that disseminating traditional texts by adapting their narrative structures as contemporary media is more prevalent in the contemporary world than in previous years.

Chinese ancient narrative theory can be found in the notes, prefaces, postscripts, and commentaries of classic novels. The four representative Chinese classic novel commentators of the Ming and Qing Dynasties were Jin Shengtan, Mao Zonggang, Zhang Zhupo, and Zhi Yanzhai (Kang, 1999; Ryu, 2011). On the basis of the definitions of narrative essays proposed by various Chinese scholars, a narrative can be divided into the following elements: narrative approach, structure, and reading $(\mathrm{Hu}, 2008)$. Western narratology is an inclusive subject that examines a work from the perspectives of form, objective discussion, and structural relationship. Chinese literary theory is the opposite. It focuses more on substantive creation or the establishment of reading rules and subjective judgment criteria (Ryu, 2011). A comparison of Chinese and Western literary theories reveals that Chinese literature does not have specific rules for narrative structure as does Western literature. Chinese literature focuses on the classification of literary genres and writing styles; for instance, Chinese literature critics tend to comment on the writing and narrative techniques of various classic novels. Such a critique style not only highlights novel authors' narrative styles and critics' perspectives on novels but also enables readers to gain a general but detailed understanding of the literary works being reviewed. When analyzing the structure of a literary work, Western critics adopt an objective perspective (i.e., exploring the work outside in), whereas Chinese critics employ subjective prin- 
ciples (i.e., exploring the work inside out). An observation of Western and Eastern views on narrative theory shows that the Western and Eastern world views share similar concepts of narrative despite time and background differences. The major difference lies in the fact that the narratology of Western novels is established through objectivity and systematic systems, whereas the narratology of Chinese novels relies on the novel itself and the writing techniques employed by the author, uniting both elements as a comprehensive whole.

\subsection{Characters in the Context of Transmedia Narratology}

Storytelling through the medium of novels is a prototype of a narrative structure that contains elements pertaining to characters, story backgrounds, events, plots, and endings. This storytelling medium can be translated into media that use visual arts such as image design, performing arts, and audiovisual media. A story refers to the "content" of a narrative whose "form" comprises core events, characters, and backgrounds (Chatman, 2000). Characters are an element of a story and notable elements include protagonists, main supporting characters, and their characteristics. According to Mao Zonggang, combining the characteristics and actions of characters can highlight their distinct personalities in the story (Zhang, 1990). Story characters, settings, backgrounds, and events are related to the plot development. Western scholars generally adopt systematic and objective viewpoints when illustrating the connections between characters and narrative, and further identify a range of basic elements associated with the story. Chinese scholars typically emphasize the presentation of the distinctive personalities of characters.

Characters play a vital role in narrative theory. Readers perceive characters' emotions through reading the text. Visual narratives can be divided into static visual narratives, dynamic visual narratives, and interactive visual narratives (Pimenta \& Poovaiah, 2010). By basing a new work on an original text, adapters translate the original text and style into a different medium, thereby reinterpreting the story through transposition. In animation adapted from literary works, characters are mostly developed through the modification of existing prototypes; for instance, animation film Frozen was adapted from "The Snow Queen," a fairy tale written by Hans Christian Andersen; Chinese animation film Monkey King: Hero Is Back was adapted from Journey to the West, a Chinese chapter novel. These stories are translated across various media (i.e., literature, picture books, and animations) with the help of modern technology, thereby creating intermediality between original and adapted works. Such intermediality involves a transition into a new form of visual narratology. Sun Wukong, also known as the Monkey King (the main character in the novel Journey to the West), is a complex, round, developed character. This characterization is reflected in the original author's textual description of the character. Thus, the story of Journey to the West can be regarded as a motif that creators subsequently adapted into various forms such as comics, picture books, animations, and mobile and virtual reality games through transposition. The perspectives of the aforementioned 
scholars indicate that characterization must be performed by considering the actions and functions of the character involved. Character personalities are constructed in literature through syntax and descriptions. They are created in stationary images depending on the designer's style and developed into dynamic images through the interplay of variables, including camera movement, image composition, rhythm, music, and voiceovers, thereby contributing to more diversified and complex intermediality.

\subsection{Characterization}

This subsection explores the definitions of characters proposed by early novelists. In terms of character development, Western scholars employ the term "characterization", whereas Chinese novelists use several terms to indicate the same meaning, including: role development, character development, role portrayal, and role depiction. Although "role" is a synonym for "character" in Chinese, "role" is used more often in literary criticism, whereas "character" is preferred in visual design. The researchers determined that this usage difference results from the fact that "role" is generally used in the context of text whereas "character" is a more appropriate term for a field where visual traits are valued over implicit characteristics. Because this study applies concepts of visual design to the comparison of texts and images, the term "characterization" was selected rather than "role development". Forster (1927) divided characters into round and flat characters. Round characters exhibit complex and diverse characteristics, whereas flat characters possess the same or similar characteristics throughout the story. Later, scholars proposed the concept of stock characters (Abrams \& Harpham, 2009; Powell, 1990), which are a category of recurring characters in literary works, such as frauds, fools, and clowns in ancient Greek comedies (Abrams \& Harpham, 2009). Joseph Ewen extended Forster's theory and positioned characters on a continuum of three axes: complexity (Simple-Complex), development (Static-Developed), and penetration into the inner life (External performance-Internal states). These axes were used to classify characters (Rimmon-Kenan, 1983). In contrast to Forster's binary classification, Ewen's characterization approach enables a more precise classification of characters by positioning them along the axes.

Chinese ancient narrative theorists focus on "role depiction"; for instance, Jin Sheng-tan's discourse on role depiction emphasizes consistency, comparison, and contrast of characters' personalities. Mao Zonggang pays more attention to the construction of "typical characters" and divided the typical characters in the Chinese novel Romance of the Three Kingdoms into complex (i.e., characters demonstrating a mix of personality traits; Zhuge Liang, Guan Yu, and Cao Cao) and simple (characters emphasizing only a single personality trait) types. Instead of focusing on characters' personalities, Zhang Zhupo focuses on characters' emotions and reasoning (qing li) and explores the master-slave relationships among characters (Ryu, 2011). In terms of the artistic approach adopted for characterization, Jin divided contrast of characters into "negative contrast" and 
"complementary contrast"; Mao proposed "negative contrast" and "positive contrast". Mao's classification is more effective than Jin's (Zhang, 1990). Mao and Forster possess similar ideas of characterization: complex and simple characters are identical to round and flat characters, respectively. Overall, Eastern novelists employ "comparison" and "contrast" methods to emphasize the peculiarities of characters.

How do novelists develop and arrange characters in a plot? This requires methods of character depiction. In Western narrative theory, "characterization" refers to the depiction of characters to the implied reader (Abrams \& Harpham, 2009; Chatman, 2000). Powell (1990) classified characterization into telling and showing. Ewen divided indicators of characterization into direct definition and indirect presentation (Rimmon-Kenan, 1983), which respectively correspond to similar terms used in Eastern narrative theory: direct and indirect description. Through textual description, the author communicates information about characters' personalities to the reader. During this process, direct description is fast and straightforward, but it reduces the personality of the literary work; indirect description requires the reader to guess, fill in the gaps, and connect the dots because it employs various events and the characteristics of specific characters, objects, or events to showcase characters' personalities.

The aforementioned definitions are mostly implicit textual indicators of characterization; on the basis of these definitions, characters can be classified into complex/round, simple/flat, and stock characters. The definitions of stock and flat characters overlap; both refer to "characters with consistent personalities throughout the story." From a broad perspective, which is adopted by the present study, "stock characters" refers to recurring characters in the plot, such as protagonists, antagonists, and clowns. The discussed approaches for classifying characterization types are mainly based on either binary classification or the comparison and contrast of characters. To precisely distinguish characters' personalities throughout a plot, the present study employs Ewen's concept of axes as a theoretical framework, supported by the aforementioned definitions of character types, in the examination of text and image samples in the following section.

\section{Method}

\subsection{Sample}

Integrating Western and Eastern views on characterization, the present study aims to incorporate the three dimensions of characters, functions, and actions (Kang, 1999; Propp, 1975) and evaluate the adaptations of Chinese classic novels (text) into explicit images according to these dimensions. The implicit characteristics of the characters in the original text are analyzed in terms of the definitions of characterization proposed by Forster, Abrams, Powell, Ewen, and Mao.

Mao exhibits a tendency to absolutize the typical characters featured in Chinese novels; for instance, he praised Zhuge Liang, Guan $\mathrm{Yu}$, and Cao Cao as 
characters with "three respective fantastic and distinguished qualities" in Romance of the Three Kingdoms (Zhang, 1990). This Chinese classic novel (1350-1400 AD.; Luo Guanzhong's version; 120 chapters in total), is selected as the research subject of the present study. The examined characters in this novel are Zhuge Liang, Guan Yu, and Cao Cao (see Table 1). Samples of images adapted from this novel were collected from the following sources: 1) zhizhi xinkan quanxiang pinghua sanguo zhi (Editorial Board of the Hanyu Da Cidian, 2002), 2) the researchers' previous survey on Taiwan's temple paintings (Lee, 1999). Romance of the Three Kingdoms (1350-1400 AD; Luo Guanzhong's version) is a classic novel comprising 120 chapters. Based on historical facts, the novel depicts the political battles and struggles between three power blocs during the Three Kingdoms period in Chinese history and features approximately 200 major characters, who are portrayed realistically and whose personalities are developed through their actions and postures. Zhizhi xinkan quanxiang pinghua Sanguo zhi (1321$1323 \mathrm{AD}$; pinghua literally means "scripts for storytellers") is a three-volume Chinese antique novel with text and illustrations comprising 68 chapters and serving as the predecessor for the Romance of the Three Kingdoms. The illustrations, printed using lithography to depict story plots, are positioned above the text.

\subsection{Procedure}

The following procedures were performed: 1) samples were collected and the chapters/episodes in which the three studied characters appear within the works were recorded; 2) the type of characterization was identified from the novel (text); 3) the visual images adapted from the text were collected from three media (namely an antique book, paintings, and an animation) and analyzed to determine the key elements of characterization involved in the adaptation process and to identify the design method employed for the adaptation (see Figure 1).

Table 1. Statistics of the image samples.

\begin{tabular}{ccc}
\hline Code number & New Edition of Romance (A) & Temple paintings (B) \\
\hline Zhuge Liang (P1) & 14 & 2 \\
Guan Yu (P2) & 16 & 12 \\
Cao Cao (P3) & 8 & 1 \\
Total number of images & 38 & 15 \\
\hline
\end{tabular}

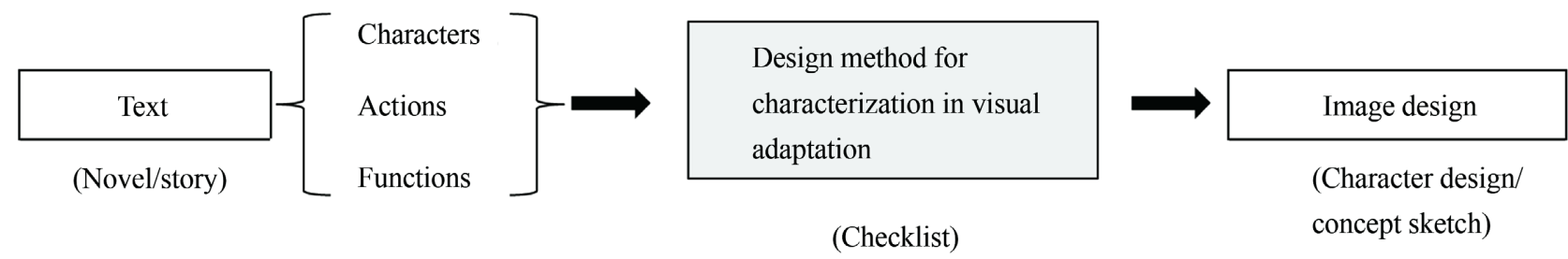

Figure 1. Adaptation process from text to image. 
This stage only aimed to identify and to examine potential design methods used for characterization in text-to-image adaptation. In a later stage, the visual image samples and story motifs were explored, and methodology verification was performed.

\section{Results and Discussion}

\subsection{Characterization in the Text}

Romance of the Three Kingdoms is known for its vividly portrayed characters, among which, three archetypal characters receive the most attention: Zhuge Liang, Guan Yu, and Cao Cao. Shen (2002) statistically deduced that the novel contains 1230 characters. Mao described Cao Cao, Zhuge Liang, and Guan Yu, respectively, as characters with legendary strategic thinking skills (due to his tactical talent as an antagonist), wisdom (due to his loyalty, intelligence, elegance, and justice), and righteousness (due to his integrity and courage as a famous general) (Zhang, 1990). These three qualities render them as stock characters in the plot structure; the characters' contrasting qualities echo the distinctiveness of these characters. Propp and Mao proposed a trinity consisting of "characters, functions, and actions" as the definition of characterization. Here, Zhuge Liang (man with wisdom), Guan Yu (man with courage), and Cao Cao (man with strategic thinking skills) correspond to their definition of "character". However, the connection between "functions" and "actions" is dependent on the events arranged for the story text. Therefore, these three characters are not portrayed with only one single image throughout the text, even though the aforementioned three distinguished qualities are their primary personality traits. The author of the novel conveys a message of "uncertainty" to the reader through textual descriptions of these characters' characteristics; these contradictory depictions create room for imaginings of the characters within the mind of the receiver. For instance, Cao Cao is described as an antagonist (primary personality) in the novel, but he also possesses heroic qualities, in addition to the generally negatively-perceived "shrewd tactical skills", because of his ability to properly employ and nurture talents and develop strategies. The author of the novel intentionally creates this ambiguity for the reader (who is left to ponder whether Cao Cao is a protagonist or antagonist).

The characterizations of Zhuge Liang (man with wisdom), Guan Yu (man with courage), and Cao Cao (man with strategic thinking skills) were analyzed in terms of the dimensions of action, function, and personality by exploring three chapters from the novel (see Table 2). In the chapter, "Borrowing Arrows with Thatched Boats", Zhuge Liang (P1) strategically obtains 100,000 arrows from his opponent. Although only a civil servant, he conquers battles of all scales by applying tactical wisdom and exhibiting loyalty, intelligence, and elegance. In the chapter, "Drowning of the Seven Armies", Guan Yu (P2) is observant of the topography of the battlefield before making a strike, a strategy through which he claims victory from Cao Cao. In his capacity as military general, Guan Yu 
Table 2. Characterization of three characters in the novel.

\begin{tabular}{|c|c|c|c|c|}
\hline $\begin{array}{l}\text { Code } \\
\text { number }\end{array}$ & $\begin{array}{l}\text { Chapter } \\
\text { number }\end{array}$ & Action & Function & Personality \\
\hline P1 & 46 & $\begin{array}{l}\text { Borrowing } \\
\text { arrows with } \\
\text { thatched boats }\end{array}$ & Wisdom & $\begin{array}{l}\text { Loyalty, } \\
\text { intelligence, } \\
\text { and elegance }\end{array}$ \\
\hline $\mathrm{P} 2$ & 72 & $\begin{array}{l}\text { Drowning } \\
\text { the seven armies }\end{array}$ & Victory in battle & $\begin{array}{l}\text { Integrity, } \\
\text { loyalty, } \\
\text { and courage }\end{array}$ \\
\hline P3 & 41 & $\begin{array}{l}\text { Zhao Zilong } \\
\text { rescues the } \\
\text { child lord }\end{array}$ & $\begin{array}{l}\text { An antagonist } \\
\text { appreciates the talent } \\
\text { of his opponent }\end{array}$ & $\begin{array}{c}\text { Strategic } \\
\text { thinking skills } \\
\text { and ambition }\end{array}$ \\
\hline
\end{tabular}

demonstrates integrity, loyalty, and courage. In the chapter, "Zhao Zilong Rescues the Child Lord", Cao Cao (P3) appreciates the talent of his opponent, Zhao Zilong, who rescues the child of his lord from Cao Cao's camp. Although he is an antagonist exhibiting Machiavellian skills and ambition, Cao Cao implicitly exhibits the personality of a protagonist in some chapters.

Preliminary analysis of the three characters in terms of the aforementioned three dimensions revealed that rather than limit a character to only one specific personality trait, the author portrays characters with one primary and two to three secondary personality traits. For instance, Zhuge Liang possesses the internal qualities of a scholar, wisdom of a strategist, and calculative skills of a Taoist. Guan Yu exhibits the courage of a military general and loyalty of a government minister. Cao Cao is depicted not only as an antagonist but also as one with the implicit qualities of a strategic thinker who appreciates talent. Moreover, in addition to direct descriptions, Chinese literature often introduces characters through profiling and metaphorical techniques to develop multiple layers of personality. For instance, in Chapter 35 of the novel, the author introduces a subplot before Zhuge Liang enters the story, where Liu Bei, who is seeking talent, fails to meet Zhuge Liang several times even after paying multiple visits.

\subsection{Sequence of the Three Characters Featured in New Edition of Romance}

In the original text of the novel, the three characters are introduced in the following order (see Table 3): Guan Yu (Chapter 1), Zhuge Liang (Chapter 5), and Cao Cao (Chapter 37). Their deaths are arranged in the order of Guan Yu (Chapter 77), Cao Cao (Chapter 78), and Zhuge Liang (Chapter 103). In the illustrated antique book New Edition of Romance, they are introduced in the order of P2 > P3 > P1, different from that in the novel (i.e., P2 > P1 > P3) and mostly featured in Volumes 2 and 3 (see Figure 2). Zhuge Liang (P1) is mostly featured in the latter halves of Volumes 2 and 3. Guan Yu (P2) and Cao Cao (P3) are featured the most in Volume 2. Guan Yu (P2) is fairly evenly featured in all three volumes. This arrangement was devised in line with the author's characterizations 


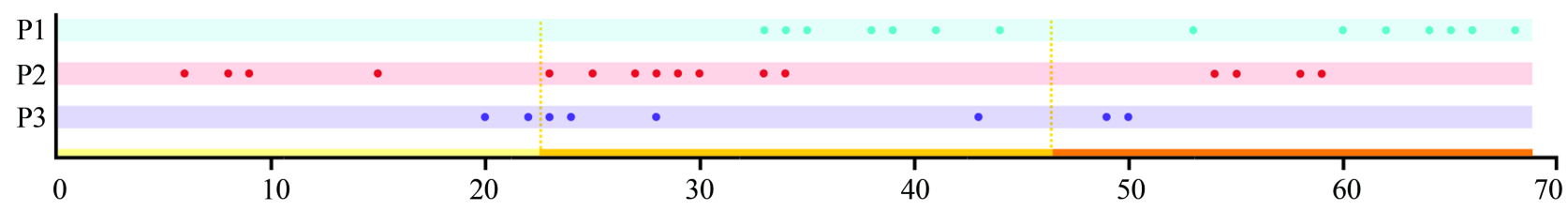

Note: P1 = Zhuge Liang, P2 = Guan Yu, P3 = Cao Cao $\quad$ Vol. $1=$ Vol. $2-$ Vol. 3

Figure 2. Sequence of the three characters being featured in New Edition of Romance.

Table 3. Numbers of appearances of the three characters featured in New Edition of Romance.

\begin{tabular}{ccccc}
\hline Code number & Type of character & Volume 1 & Volume 2 & Volume 3 \\
\hline P1 & Protagonist & 0 & 7 & 7 \\
P2 & Protagonist & 4 & 8 & 4 \\
P3 & Antagonist & 2 & 4 & 2 \\
\hline
\end{tabular}

of the three characters. At the beginning of New Edition of Romance, Guan Yu (P2), a protagonist who exhibits loyalty, courage, and righteousness, is introduced. Cao Cao (P3) is introduced as an antagonist toward the end of Volume 1. The aforementioned three characters all feature in Volume 2. In Volume 3, the death of the antagonist precedes that of the two protagonists. In summary, Volumes 1, 2, and 3 mainly feature Guan Yu (protagonist) and Cao Cao (antagonist), all three characters (two protagonists and one antagonist), and Zhuge Liang (protagonist), respectively. All three characters appear in Volume 2. The death of the antagonist precedes that of the protagonists (i.e., in the order of P3, P1, and P2). Thus, the narrative structure of New Edition of Romance and the sequence of the three characters featured in this classic story follow the traditional narrative model of Chinese literature: The protagonists win eventually and feature more than the antagonists in the story.

\subsection{Plotting of Characters along Axes}

Phrases used for describing the physical attributes of these characters were collected from the novel (see Table 4). An analysis of these phrases determined that the novel's author intended to depreciate the antagonist through height differences. For instance, among these three characters, Guan Yu (protagonist/general) is the tallest and Cao Cao (antagonist/treacherous government minister) is the shortest. Height difference signifies a consistent pattern in the body sizes of the protagonists and antagonists that is often employed in traditional stories, namely that a hero must be physically superior to a villain. For instance, superman has an inverted triangular and muscular body. In the novel, the characters' heights are calculated using the unit of chi (Chinese foot) first adopted in the Han Dynasty. When their heights are converted into centimeters, the protagonists are revealed as unusually high for Chinese people. Therefore, when depicting the protagonists, this historical novel seems to enhance visual images in 
Table 4. Textual descriptions of the characters' physical attributes.

\begin{tabular}{|c|c|c|c|}
\hline $\begin{array}{l}\text { Code } \\
\text { number }\end{array}$ & $\begin{array}{l}\text { Textual description and } \\
\text { number of mentions }\end{array}$ & Personality & $\begin{array}{c}\text { Stock } \\
\text { character }\end{array}$ \\
\hline P1 & $\begin{array}{l}\text { Holding a feather fan in hand (18), } \\
\text { wearing a green silk headscarf (13), } \\
\text { covered in a crane feather coat (13), } \\
\text { complexion like fine jade (2), } \\
\text { eight chi in height (1) }\end{array}$ & $\begin{array}{l}\text { Loyal, } \\
\text { intelligent, } \\
\text { and elegant }\end{array}$ & A sage \\
\hline $\mathrm{P} 2$ & $\begin{array}{l}\text { The Green Dragon Crescent Blade (25), } \\
\text { complexion like red jujubes (4), } \\
\text { slanted eyes (4), } \\
\text { eyebrows in the shape of a reclining } \\
\text { silkworm (4), } \\
\text { beard with a length of two chi(2), } \\
\text { red lips (2), nine chi in height (1) }\end{array}$ & $\begin{array}{c}\text { Loyal, } \\
\text { courageous, } \\
\text { and righteous }\end{array}$ & $\begin{array}{c}\text { A famous } \\
\text { general/hero }\end{array}$ \\
\hline P3 & $\begin{array}{l}\text { seven chi in height ( } 1) \text {, } \\
\text { small eyes and a long beard ( } 1 \text { ) }\end{array}$ & $\begin{array}{l}\text { Treacherous } \\
\text { and heroic }\end{array}$ & $\begin{array}{c}\text { A treacherous } \\
\text { government } \\
\text { minister }\end{array}$ \\
\hline
\end{tabular}

readers' minds by overestimating or exaggerating the characters' physical attributes. The three main characters analyzed in the present study represent the antagonist, protagonist, and sage; two are loyal and one is treacherous. These types of recurring characters are commonly employed in both Eastern and Western narratives.

By integrating an Eastern narratology perspective with the text studies on Romance of the Three Kingdoms, this study determined that these characters belong to the categories of round and complex characters and display various unpredictable traits. From a broad perspective, they also exhibit characteristics of stock characters. In other words, character frameworks are assigned from the implied author through the role of the narrator, to define these characters. These frameworks include antagonist, protagonist, sage, courageous, and treacherous. In this study, Cao Cao, Zhuge Liang, and Guan Yu were positioned along three axes (see Figure 3), When plotted along the "simple-complex" axis, the three characters are considered as complex and round characters, which is common for lead characters in a story. By contrast, supporting characters are developed as simple and flat. For instance, Zhao Yun is a character who devotes his life to being loyal to his lord. When positioned on the "static-developed" axis, Cao Cao and Zhuge Liang are regarded as developed characters who undergo certain changes as the story progresses. By contrast, Guan Yu exhibits loyalty and righteousness throughout the story. Consisting of "Simple-Complex," "Static-Developed," and "Direct description-Indirect description". The axis of "Direct description-Indirect description" assesses how the author of the novel uses words to describe a character. For instance, the author of the novel shapes Cao Cao's image through the conversations of the other characters (e.g., 


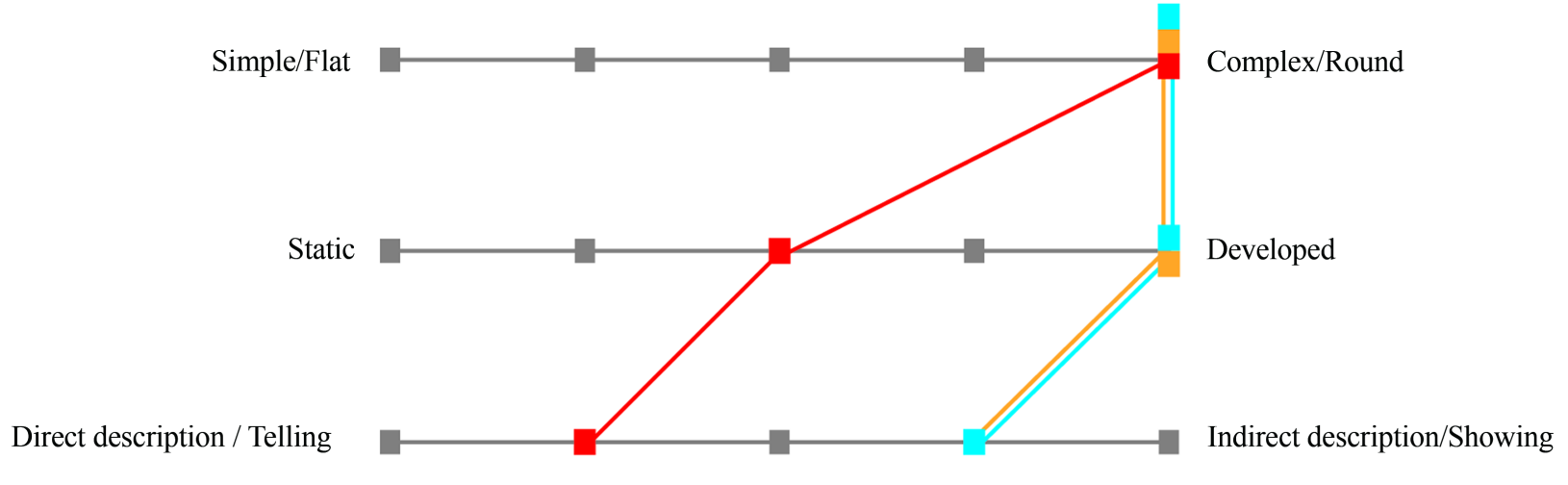

$\mathrm{P} 1 \square \quad \mathrm{P} 2 \square \quad \mathrm{P} 3$

Figure 3. Character classification along three axes.

describing him as "cunning and treacherous" and "skilled in developing tactics"). The axis of "penetration into the inner life" proposed by Ewen requires a study of the full text, and thus was excluded from the present study.

\subsection{Pictorial Elements for Characterization}

A cross-examination of textual descriptions in the novel and collected visual images revealed that the following elements are crucial for characterization: 1) body shape, 2) facial features, 3) clothing, and 4) accessories (see Table 5). In the novel and visual representations, the authors emphasize contrasts in height, facial features, and colors to develop characters' personalities. The feather fan and green silk headscarf of Zhuge Liang (P1) suggest a composed attitude, whereas his cloak (a typical apparel for Taoist priests) adorns him with the professional image of specializing in divination, an ancient form of divination in China and magic skills, contrasting his soft qualities as an attractive-looking scholar. Guan $\mathrm{Yu}(\mathrm{P} 2)$ is the tallest of the three characters. Portrayed as a military general, he possesses typical Chinese facial features such as slanted eyes (a common attribute in ancient Chinese paintings) and eyebrows in the shape of reclining silkworms (i.e., pretty ebony-black eyebrows with slightly upward-curving ends that resemble silkworms when viewed from a distance), a term for brow shape also used for character descriptions in the classic Chinese novel, Water Margin (also known as Outlaws of the Marsh). Guan Yu has a dark red skin tone. In Peking opera, face paint color has a significant meaning for each character; red signifies loyalty, righteousness, and integrity (qualities of a protagonist) and is mostly used for talented generals or people attaining spiritual immortality or enlightenment. The Green Dragon Crescent Blade is Guan Yu's weapon of choice. Readers familiar with the story know that this weapon is a representation of Guan Yu and is indispensable to him. Cao Cao (P3) has small eyes and a long beard and is dressed in the clothing of a Chinese official. His slightly slouched posture and facial features adorn him with the image of a calculated, shrewd, tactical person. 
Table 5. Analysis of elements for characterization.

\begin{tabular}{|c|c|}
\hline \multicolumn{2}{|c|}{ P1 (Zhuge Liang) } \\
\hline $\begin{array}{l}\text { Height: eight chi } \\
\text { (approximately } 184 \mathrm{~cm} \text { ) }\end{array}$ & $\begin{array}{c}\text { Apparel: } \\
\text { a green silk headscarf and a cloak } \\
\text { (a typical apparel for Taoist priests) }\end{array}$ \\
\hline Facial features: attractive face & Accessory: a feather fan \\
\hline \multicolumn{2}{|c|}{ P2 (Guan Yu) } \\
\hline $\begin{array}{l}\text { Height: nine } c h i \\
\text { (approximately } 207 \mathrm{~cm} \text { ) }\end{array}$ & Apparel: clothes in green \\
\hline $\begin{array}{l}\text { Facial features: slanted eyes, eyebrows } \\
\text { in the shape of a reclining silkworm, } \\
\text { dark red skin tone, bright red handsome } \\
\text { lips, and a beard with a length of } \\
\text { two chi (approximately } 46 \mathrm{~cm} \text { ) }\end{array}$ & $\begin{array}{c}\text { Accessories: } \\
\text { Green Dragon Crescent Blade } \\
\text { and the famous horse, Red Hare }\end{array}$ \\
\hline \multicolumn{2}{|c|}{ P3 (Cao Cao) } \\
\hline $\begin{array}{l}\text { Height: seven } c h i \\
\text { (approximately } 161 \mathrm{~cm} \text { ) }\end{array}$ & $\begin{array}{c}\text { Apparel: } \\
\text { Chinese official's hat and a red shawl }\end{array}$ \\
\hline $\begin{array}{c}\text { Facial features: } \\
\text { Small eyes and a long beard }\end{array}$ & Accessory: No specific accessory \\
\hline
\end{tabular}

The preceding analysis revealed that body shape is a basic element for characterization; for instance, Guan $\mathrm{Yu}$ is a military general with a tall, inverse triangular body, a common hero's body type in contemporary comics and animations. Facial features serve to depict characters' deeper traits. One of the most stereotypical facial features of Chinese people to Westerners is slanted eyes, which can be seen in contemporary animations depicting Chinese characters such as Mulan, an American animated film by the Walt Disney Company. Specifically, a comparison of the visual images of Guan Yu and Cao Cao revealed that eye shapes indicate specific personality traits; Guan Yu's slanted eyes and Cao Cao's small eyes represent a courageous man and a treacherous government minister, respectively. Moreover, positive contrasts are implied by characters' clothing and accessories. Therefore, the characters' personalities are clearly defined. The character-accessory pairings have metaphorical meanings for a character's traits; for instance, Guan Yu's Green Dragon Crescent Blade represents integrity and justice. This is one example of how weapons are indispensable objects for the three characters in the story because they visually represent these characters' personalities.

\subsection{Cross Analysis}

Contemporary scholars have interpreted Zhuge Liang, Guan Yu, and Cao Cao as men with wisdom, courage, and strategic thinking skills, respectively. From a Western writing perspective, rather than limit a character to only one specific personality, the author portrays a character with one primary and multiple sec- 
ondary personalities. For instance, Zhuge Liang follows the character progression of living a pastoral lifestyle and subsequently serving as prime minister, a strategist, and finally a Taoist priest. Analyses of these three characters' progressions, durations of being featured in the novel, and visual image samples revealed that the two protagonists are featured more in the story than is the antagonist. Zhuge is mostly featured in Volumes 2 and 3 of New Edition of Romance. In the image samples, Guan $\mathrm{Yu}$ is considered as a stock character that displays consistent excellence in fighting skills, which is illustrated through a dynamic posture. By contrast, the images of Cao Cao are mostly static and illustrate his standing or sitting postures. The sequence of the three characters in the illustration sample was determined on the basis of the novel's chapters. However, differences in the characters' positions on the characterization axes were noted between the text and image (illustration). In the text, the characters are mostly positioned on the right side of the axes in the following order: P1 (Zhuge Liang), P3 (Cao Cao), P2 (Guan Yu). In the image samples, the characters are also primarily positioned along the right side: P1 (Zhuge Liang), P3 (Cao Cao), P2 (Guan Yu). This study developed a method of evaluating characterization (Table 6) by incorporating the following critical elements of characterization in Western and Chinese literature: character name, stock character type, and implicit and explicit characteristics. Stock character type suggests a character's primary personality, which moves toward the right side of the axis when infused with multiple secondary implicit personalities, and vice versa. Overall, in the examined works, leading characters are mostly positioned on the right side of the axis, whereas secondary characters are mostly positioned on the left side. More case studies are required to support this statement.

Through the East and West definitions of characterization, this study developed an evaluation form for characterization (see Table 6). In general, visual designers create concept sketches to initiate the creative process. However, the

Table 6. Evaluation form for characterization.

\begin{tabular}{c}
\hline Character name: \\
RProtagonist $\square$ Antagonist $\square$ Clown $\square$ Supporting character $\square$ Other \\
Simple/Flat \\
Static \\
Direct description/Telling \\
Body shape: \\
Facial feature: \\
Applicit
\end{tabular}


proposed form is used for developing ideas after exploring the original text and before creating sketches; therefore, it is helpful for realizing creative concepts through an classification of implicit and explicit factors that affect characterization during the process of adapting literature into images.

\section{Conclusion}

Textual analysis was performed on the classic Chinese novel Romance of the Three Kingdoms to identify how the three main characters are developed in the text. Mao described these three characters as having distinctive qualities. Western and Eastern narratologies were used to examine the characterization methods employed in the original text and some images adapted from the text. The preliminary findings of these methods are as follows:

Eastern and Western theories of characterization were adopted in this study to classify the aforesaid characters by positioning them on axes used for determining character types. Contrasting words were placed on the ends of the axes to explain the nuances of character development. For instance, "Round/Complex" and "Simple/Flat" are two pairs of contrasting words that were used to describe the characteristic variations in the characters within the story. The three characters in the sample belong to the "Round/Complex" type. The axis of "Static-Developed" was used to depict a character's development potential in the story. The overall development potential can be adequately observed in both the novel and the samples. However, the antique book contains more text than illustrations, and therefore it did not provide sufficient information for interpreting the development of the characters. The axis of "Direct description-Indirection description" reflected how the different creators use words to describe the characters. This depends on the writing style of each creator. However, the novel uses more indirect than direct descriptions to create room for the reader's imagination. In addition, the "comparison" and "positive contrast" methods featured in Eastern narratology were observed in the textual descriptions of the characters and their visual designs. A cross-examination of those textual descriptions and visual images determined that, to capture the essence of a character's characteristics, one should consider the following factors: the character's body shape, facial features, apparel, accessories, and whether he or she is a stock character.

Eastern and Western academic fields have long debated and proposed numerous frameworks pertaining to narrative theories and narratology. However, how to apply such theories in education warrants further investigation. By incorporating the definitions of characterization in Western and Eastern narrative theories and identifying the elements of characterization employed in text and visual images, this study hoped to provide inspiration and a reference for novice designers attempting to create images based on literary works. At this stage of study, the characterization methods employed by each creator were not analyzed using a qualitative approach. Therefore, further investigation can adopt focus interviews with newly employed image designers, illustrators, and animation designers. 


\section{Conflicts of Interest}

The authors declare no conflicts of interest regarding the publication of this paper.

\section{References}

Abrams, M. H., \& Harpham, G. G. (2009). A Glossary of Literary Terms. Boston: Wadsworth Cengage Learning.

Chatman, S. B. (2000). Story and Discourse: Narrative Structure in Fiction and Film. New York: Cornell University Press.

Editorial Board of the Hanyu Da Cidian (2002). A Collection of Ancient Chinese Novel Illustrations. Shanghai: Hanyu Da Cidian Publishing and Shanghai Century Publishing Group.

Forster, E. M. (1927). Aspects of the Novel. London: Penguin Books.

Hu, Y. M. (2008). Narratology. Wuhan: Huazhong Normal University Press.

Kang, L. H. (1999). Studies into the Theories of Late Qing Fiction. Taipei: Daan Publishing.

Lee, H. L. (1999). Research of Relations between Portrait and Meanings. Example Taken through 1st and 2nd Class Ancient Temple Relics in Taiwan (pp. 33-81). Master's Dissertation, YunTech.

Pimenta, S., \& Poovaiah, R. (2010). On Defining Visual Narratives. Design Thoughts, 3, 25-46.

Powell, M. A. (1990). What Is Narrative Criticism. Minneapolis: Fortress Press.

Propp, V. (1975). Morphology of the Folktale. Austin: University of Texas.

Rimmon-Kenan, S. (1983). Narrative Fiction: Contemporary Poetics. London: Routledge. https://doi.org/10.4324/9780203130650

Ryan, M. L. (2004). Narrative across Media. Lincoln: University of Nebraska Press.

Ryu, S. J. (2011). A Narrative Study of "The Journey to the West". New Taipei City: Hua$\mathrm{Mu}-$ Lan Culture Publishing.

Shen, P. C. (2002). On the Three Kingdoms: Characters, Plots, and Famous Scenes, Taipei: Yuan-Liou Publishing Co., Ltd.

Stanczak, G. C. (2007). Visual Research Methods: Image, Society, and Representation. London: Sage. https://doi.org/10.4135/9781412986502

Zhang, M. J. (1990). A Study of Ming-Qing Fiction Commentary. Ph.D. Dissertation, Soo Chow University. 